\title{
Study and promotion of safety culture using mixed methods research
}

Original article

\author{
Daiane Brigo Alves ${ }^{a}$, Elisiane Lorenzinib,*, Nelly Oelke ${ }^{c}$, Anthony John Onwuegbuzie ${ }^{d}$, \\ Adriane Cristina Bernat Kolankiewicza \\ ${ }^{a}$ Department of Life Sciences, Regional University of the Northwest of the State of Rio Grande do Sul (UNIJUI), Rio Grande do Sul 98700-000, Brazil \\ ${ }^{b}$ Nursing Department, Federal University of Santa Catarina, Florianópolis, Santa Catarina 88040-900, Brazil \\ 'School of Nursing, Faculty of Health and Social Development, University of British Columbia, Okanagan, British Columbia V1V 1V7, Canada \\ ${ }^{d}$ Faculty of Education, University of Cambridge, Cambridge CB2 $8 P Q$, United Kingdom
}

Received: 28 August 2020; Accepted: 21 October 2020; Published: 20 June 2021

\begin{abstract}
Objective: With a positive safety culture, institutions offer the best quality and safe care to their patients. The objective of this study was to analyze patient safety culture from the perspective of the multidisciplinary team, to identify factors that influence patient safety culture, and to create/promote-jointly with the study participants-strategies for improving processes of change.

Methods: The study design represented a mixed methods research approach, with a sequential explanatory design. A multidisciplinary team of workers at a general hospital was eligible for the study. To collect quantitative data, we administered the Safety Attitudes Questionnaire (SAQ). The qualitative phase was accomplished via focus groups (FGs), with participants from the first phase of the study using the principles of deliberative dialogue (DD) as a knowledge-translation strategy. The STROBE guideline was used to develop the study.

Results: The overall SAQ score was positive $(75.1 \pm 10.4)$. Negative scores were found in the fields of Safety Climate, Working Conditions, and Stress Recognition. Focus group discussions identified the aspects that create a negative impact on safety culture, such as ineffective communication, punitive approach in the event of errors, the lack of commitment and adherence to the protocols, and the non-recognition of the stress and the mistakes. Actions for the promotion of safety culture were developed and implemented during the study.

Conclusions: The use of the principles of DD as a strategy for knowledge translation (KT) made it possible to identify and plan for joint actions to generate improvements in safety culture.
\end{abstract}

Keywords: deliberative dialogue $\bullet$ knowledge translation $\bullet$ mixed methods $\bullet$ organizational culture $\bullet$ patient safety

(C) Shanxi Medical Periodical Press.

\section{Introduction}

Patient safety has been widely discussed by researchers and policy makers and is challenging for healthcare organizations. ${ }^{1}$ At the same time, users expect highquality, error-free care from health-service providers.
It has become clear that patient safety issues are more complex than initially understood since the health care system continues to operate with a low degree of reliability, indicating that patients often suffer harm that

How to cite this article: Alves DB, Lorenzini E, Oelke N, Onwuegbuzie AJ, Kolankiewicz ACB. Study and promotion of safety culture using mixed methods research. Front Nurs. 2021;2:129-140. 
could have been avoided. ${ }^{2,3} \mathrm{~A}$ recent study revealed that 1 out of every 10 patients developed an adverse condition during hospitalization. Furthermore, findings from this study showed that more than 12 million patients face diagnostic errors as outpatients each year. It is worth noting that more than $60 \%$ of health care errors are considered preventable. ${ }^{4}$

In Brazil, patient safety has been emphasized since 2013, with the creation of the National Patient Safety Program (NPSP), ${ }^{5}$ which advocates for the creation of patient safety teams in health establishments. The federal government initiative aims to encourage and support actions directed toward patient safety. One of the initial strategies of NPSP is the promotion of the patient safety culture, which encompasses a set of attitudes, perceptions, values, and individual and group competencies and behavioral standards that determine commitment, style, and proficiency in terms of issues related to patient safety and health management, thereby ensuring that healthcare institutions remain simultaneously profitable for the stakeholders and safe for the patients. ${ }^{6}$

Evaluating and understanding the culture of safety in healthcare facilities is essential, and, ideally, this assessment should be performed prior to planning actions that aim to provide safe care. One of the key benefits of this type of evaluation is to obtain a concrete indicator of the current state of the safety culture. ${ }^{7}$ This measurement can be performed using score-validated instruments, such as the Safety Attitudes Questionnaire (SAQ), ${ }^{8}$ which provides a temporal assessment of the institutional safety climate.

Evaluation research in this field has provided evidence of weaknesses in the safety climate in health institutions. , $^{7-11}$ Similarly, a systematic review showed the existence of limited or even insufficient evidence to define strategies capable of obtaining definitive results in improving the safety climate. ${ }^{6}$

To study patient safety culture through mixed methods, research approaches contribute, in a way, to measure the safety climate and, more importantly, to identify factors that influence the quality of care and the safety culture. ${ }^{11}$ In addition, the use of knowledge translation (KT) strategies, such as the use of the principles of deliberative dialogue (DD) during the implementation of the research, enables the participants to co-create and to identify priority actions to initiate processes of change. ${ }^{12}$ This type of approach promotes a safety culture that is essential in the search for care that constantly endeavors to preclude all possibilities for harm. ${ }^{11}$ Rationale for a mixed methods research approach is justified through the integration of quantitative and qualitative data providing a broader understanding of the research problem, going beyond the use of mono-method research.
Given these considerations and the relevance of patient safety, the following research question was studied: What are the safety culture and the respective strategies to improve the same, from the perspective of a multidisciplinary team? The study aimed (a) to analyze the patient safety culture from the perspective of the multidisciplinary team of a hospital in the southern region of Brazil; (b) to identify factors that influence the patient safety culture; and (c) to create/foster, jointly with the study participants, strategies to improve the processes of change in the patient safety culture at the study location.

\section{Methods}

The present study involved the use of a mixed methods research approach, with an explanatory sequential research design, which was denoted by QUAN $\rightarrow$ QUAL, wherein the uppercase letters indicate the phase that was prioritized-in this case, both phases had approximately equal priority-and the arrow indicates that the phases were performed sequentially. ${ }^{13}$ This method involves quantitative and qualitative data in a new framework to think about research in health services, with the potential to generate meta inferences and unique insights about phenomena that are expressed in a multifaceted way. ${ }^{14-16}$ Attention to the integration of both databases, in the design stages of the study, in the method, and in the interpretation and presentation of the results, can improve the quality of mixed methods research studies in the health area and, therefore, generate important evidence to improve health care, services, systems, and policies. ${ }^{17}$ The STROBE guideline was used to develop the study.

\subsection{Setting and sample}

The study was conducted in a general hospital in the northwest region of the state of Rio Grande do Sul, Brazil. Of the 235 employees of the institution, 222 were eligible to participate in our homogeneous sampling. ${ }^{18}$ The inclusion criteria were as follows, namely, working in the ward for at least 1 month and working at least $20 \mathrm{~h}$ per week. It is considered that with a minimum 1-month of experience and $20 \mathrm{~h}$ per week at the same institution, healthcare professionals would already perceive the values, attitudes, perceptions, and competencies at individual and group levels that determine the commitment, style, and proficiency regarding patient safety issues at the health institution. ${ }^{8}$ Temporary workers, interns, and those who were on sick leave and vacations during the data collection period were excluded. For the qualitative phase, the following inclusion criteria were added, namely, having participated in the quantitative stage of the study. 


\subsection{Quantitative phase}

Quantitative data collection was performed between November 2017 and February 2018, through the SAQ, ${ }^{8}$ a score-validated instrument for the Brazilian scenario, ${ }^{19}$ with good psychometric properties. Authorization was requested from the main author for the use of the SAQ, and permission was provided to use the tool in this research study. The instrument consists of two parts: (a) 36 items that assess the attitudes and perceptions of the team, related to the domains of teamwork climate, safety climate, job satisfaction, stress recognition, perceptions of management, and working conditions and (b) 6 items that aim to characterize the study participants. For Part 1 of the questionnaire, response options represented a 5-point, Likert-format scale, with the following options: totally disagree $(A)$, partially disagree $(B)$, neutral $(C)$, partially agree (D), totally agree (E), and does not apply (X).

Of the eligible members of the multidisciplinary team and the support service, 199 workers signed the Ethical Informed Consent and participated in this phase, which corresponds to $84.6 \%$ of the total employees of the institution. A total of 23 eligible participants have not indicated their willingness to participate.

The Statistical Package for Social Science (SPSS) Version 17.0 was used to analyze the descriptive data. The scoring on the SAQ instrument ranges from 0 to 100 , where 0 represents the worst perception of the safety climate and 100 represents the best perception. The scoring is ordered as follows: "Disagree strongly" $(A)$ is equal to 0 points; "Disagree slightly" $(B)$ is equal to 25 points; "Neutral" $(\mathrm{C})$ is equal to 50 points; "Agree slightly" (D) is equal to 75 points; and "Agree strongly" $(E)$ is equal to 100 points. The items are organized by domains. The mean of the domains was calculated as required to follow the score-validated questionnaire interpretation. ${ }^{8}$ The responses for the items in each domain are added together and divided by the number of items in that domain. For example, the perceptions of management domain are composed of 6 items; if a participant's response to those 6 items were "Neutral" (50 points), "Agree slightly" (75 points), "Neutral" (50 points), "Disagree slightly" (25 points), "Neutral" (50 points), and "Agree slightly" (75 points) respectively, the total value of the score in this domain would be 54.16, obtained using the following calculation:

$$
\frac{50+75+50+25+50+75}{6}=54.16
$$

The analysis was performed through the use of descriptive statistics, presenting measures of central tendency (mean and median) and variability (standard deviation and interquartile amplitude), as well as absolute $(N)$ and relative (\%) distribution. The symmetry of the continuous distributions was evaluated by the Kolmogorov-Smirnov test.

\subsection{Qualitative phase}

Qualitative data were collected through focus groups (FGs), the aim of which was to collect information on a given topic through discussion among participants that occurred in the same place over a certain period..$^{20}$ Recruitment for the FGs occurred through posters throughout the workplace. In addition, a smaller sample of stakeholders was personally invited to deepen and to explain the results obtained through the SAQ and to construct, jointly, strategies to implement changes in the patient safety culture. A total of 9 professionals, all considered as stakeholders, who participated in the quantitative phase, participated in the first FG meeting and 8 participated in the second FG meeting.

To increase the applicability of the research results in practice, the principles of DD were employed in the FG sessions. ${ }^{21}$ DD is based on philosophical assumptions of critical pedagogy, which are expressed in the reflective dialogue to generate actions, changes, and transformation. ${ }^{22}$ It involves the use of a participatory approach, wherein engagement in dialogue promotes understanding about the problems and the people who participate in dialogue. In DD, purposely selected activities are used, such as providing a summary of scientific evidence on the subject in question for reading a few days before the session, brainstorming, and identifying priorities. These actions serve to engage the participants (stakeholders) for the joint creation of solutions to facilitate practice change in health services. ${ }^{12,21,23}$

The main researcher [DB], who also moderated the FG, coordinated qualitative research activities. A non-participant observer, Master Student, was used for logistic support, such as the handling of recorders, registration of nonverbal information, and the organization of a coffee break. The FG sessions (each lasting $90 \mathrm{~min}$ ) were audio-recorded using two digital recorders placed in different locations of the room to ensure that the entire conversation was captured.

In the first FG meeting, the results of the quantitative stage of the study were presented, and the factors influencing patient safety culture were discussed. For the second FG meeting, a 12-page synthesis was developed based on the results of the SAQ, the feedback of the participants of the initial FG, and the scientific evidence extracted through an integrative literature review developed during our study. The synthesis was provided to participants $10 \mathrm{~d}$ prior to the second FG meeting for prior reading, to provide a shared understanding to the participants on the topic to be discussed. 
During the second FG meeting, the participants were encouraged to define strategies to implement improvements in the patient safety culture, based on the materials shared in the synthesis and their own experiences in the local context. In this meeting, the principles of DD 11,12,23,24 were employed to increase the applicability of research results at the study location. This means actions such as the following: actions that aim at the identification and planning of joint actions to generate improvements in safety culture, actions that are based on tacit knowledge and local context of the stakeholders, and so forth. Therefore, this was an Integrated Knowledge Translation (IKT) approach by facilitating the co-development of solutions, ${ }^{24}$ which facilitates better implementation of evidence into practice. An IKT approach refers to collaboration between researchers and decision-makers in an attempt to ensure that they engage in a mutually beneficial research study or program of research to support decision-making. IKT aims to generate knowledge for optimizing health care delivery systems and for improving health system performance and associated outcomes. ${ }^{25}$

We used classical content analysis as our qualitative data analysis to identify common themes. This analysis was conducted interactively and dynamically, integrating the IKT process, observing the strategy proposed in the Integrated Framework, ${ }^{26}$ and, with the analytical strategy of categorization and connection (search for small stories, contexts, and connections between texts and meanings), balancing with interpretation strategies. Approximately 2 months after the FGs had been completed, a visit was made to the nursing manager to obtain feedback and to talk about the implementation of the actions proposed by the participants during the study.

Ethical aspects related to research involving humans were respected. This study was approved by the Ethics Committee of the Regional University of the Northwest of the State of Rio Grande do Sul (UNIJUÍ) (IRB approval number: $2,355,933)$.

\section{Results}

\subsection{Quantitative findings}

In this study, women workers predominated (73.4\%; $n=146)$, and these participants were between 31 years and 50 years of age $(61.8 \% ; n=123)$. The highest percentage of participants were nurses $(55.8 \% ; n=111)$, followed by the support team $(29.6 \% ; n=59)$. Of the total number of workers, $30.3 \%(n=60)$ reported having another employment and $73.9 \%(n=147)$ were professionals of the multidisciplinary team who attended patients directly. Regarding the length of time worked at the institution, $39.2 \%(n=78)$ reported having been working more than 10 years; $28.6 \%(n=57)$ had been working from 1 year to 5 years; and $22.1 \%(n=44)$ reported having been working from 5 years to 10 years. All characteristics of study participants are shown in Table 1.

\begin{tabular}{|c|c|c|}
\hline \multirow{2}{*}{ Variables } & \multicolumn{2}{|c|}{ Total participants $(n=199)$} \\
\hline & $N$ & $\%$ \\
\hline \multicolumn{3}{|l|}{ Sex } \\
\hline Female & 146 & 73.4 \\
\hline Male & 53 & 26.6 \\
\hline \multicolumn{3}{|l|}{ Age group } \\
\hline 18 to 30 & 45 & 22.6 \\
\hline 31 and 50 years & 123 & 61.8 \\
\hline 51 or more & 31 & 15.6 \\
\hline \multicolumn{3}{|l|}{ Education } \\
\hline Elementary school & 18 & 9.0 \\
\hline High school & 124 & 62.3 \\
\hline University graduate & 24 & 12.1 \\
\hline Post-University graduate & 33 & 16.6 \\
\hline \multicolumn{3}{|l|}{ Office } \\
\hline Nursing team* & 111 & 55.8 \\
\hline Other health professionals** & 13 & 6.5 \\
\hline Doctors & 16 & 8.0 \\
\hline Support team ${ }^{\star * *}$ & 59 & 29.6 \\
\hline \multicolumn{3}{|l|}{ Work shift } \\
\hline Daytime & 138 & 69.3 \\
\hline Nightly & 61 & 30.7 \\
\hline \multicolumn{3}{|l|}{ Has another job } \\
\hline Yes & 60 & 30.3 \\
\hline No & 139 & 69.7 \\
\hline \multicolumn{3}{|l|}{ Direct work with the patient } \\
\hline Yes & 147 & 73.9 \\
\hline No & 52 & 26.1 \\
\hline \multicolumn{3}{|l|}{ Time in the institution } \\
\hline Less than 1 year & 20 & 10.1 \\
\hline 1 to 5 years & 57 & 28.6 \\
\hline 5 to 10 years & 44 & 22.1 \\
\hline Over 10 years & 78 & 39.2 \\
\hline
\end{tabular}

Source: Research data, ljuí/RS, Brazil, 2019.

Note: "Nurses, technicians, and nurse aids; " Social worker, pharmacist, dietitian, psychologist, pharmacy assistant, radiology technician;

"*x Professional hygiene service and cleaning, kitchen and pantry service, maintenance, porters, administrative managers, storekeeper, secretaries telephone operators, receptionists, and others.

Table 1. Sociodemographic and employment data for multidisciplinary team member participants. 
As shown in Table 2, on average, the domains job satisfaction (88.7), work climate team (78.8), unit perceptions of management (77.1), and hospital perceptions of management (75.4) yielded positive scores (i.e., $\geq 75$ ). In contrast, on average, the domains safety climate (72.7), working conditions (71.7), and stress recognition (59.1) yielded negative scores (i.e., <75).

\subsection{Qualitative findings}

In the first FG meeting, the results of the quantitative stage and the factors that negatively influenced the patient safety culture in the institution were discussed. Regarding the safety climate domain, the participants mentioned the lack of commitment of the professionals, the non-recognition of errors, the punitive culture, the ineffective communication, and the lack of adherence to the protocols as contributing factors for the low score. The speeches of the participants about the domain working conditions evidenced weaknesses in the infrastructure-namely, the unavailability of financial resources and materials. Regarding the low stress recognition, the participants related the result to the punitive culture and to the lack of companionship among work colleagues. Thus, they revealed that they often did not admit that they were tired or overloaded when they were asked to remain for more than 1 shift at work. Similarly, they reported that they did not previously think about the double working hours and their possible implication in patient safety.
In the second FG meeting, the participants were encouraged to think about strategies that could be implemented to initiate improvements in the safety culture. The priority actions pointed out by the group are listed in Figure 1.

Data collected from the nursing management after the FGs included the following actions:

(a) A meeting, involving the patient safety team, the managers of the nutrition, pharmacy, and nursing services as well the clinical director, technical director, and the director of the support services was carried out to present and discuss the patient safety plan of the institution because the participants of the FG pointed out the lack of knowledge of the multidisciplinary team about the patient's safety actions. During this meeting, each leader undertook to share the patient safety plan with all of her/his team's professionals. It is worth noting that, until then, the institution's Safety Plan was only directed to the nursing area;

(b) The nursing management brought together the nursing coordinators of all shifts to present the results of the existing safety indicators in the institution to identify potential threats and help to prioritize actions to avoid adverse events. Each nurse leader committed to gather their team to discuss the results of the indicators related to their work units;

\begin{tabular}{|c|c|c|c|c|c|c|}
\hline \multirow{3}{*}{ Domains } & \multicolumn{6}{|c|}{ Total population $(N=199)$} \\
\hline & \multirow[b]{2}{*}{ M } & \multirow[b]{2}{*}{ SD } & \multirow[b]{2}{*}{ Median } & \multicolumn{2}{|c|}{ Ranking* } & \multirow[b]{2}{*}{ Cronbach's alpha } \\
\hline & & & & $\begin{array}{c}\text { Low }(<75) \\
n(\%)\end{array}$ & $\begin{array}{l}\text { High } \\
\left({ }^{*} 75\right) \\
n(\%) \\
\end{array}$ & \\
\hline Full scale & 75.1 & 10.4 & 76.4 & $86(43.2)$ & $113(56.8)$ & 0.85 \\
\hline Teamwork climate & 78.8 & 14.2 & 79.2 & $62(31.2)$ & $137(68.8)$ & 0.75 \\
\hline Safety climate & 72.7 & 15.1 & 75.0 & $93(46.7)$ & $106(53.3)$ & 0.72 \\
\hline Job satisfaction & 88.7 & 13.5 & 95.0 & $21(10.6)$ & $178(89.4)$ & 0.71 \\
\hline Stress recognition & 59.1 & 27.1 & 62.5 & $120(60.3)$ & $79(39.7)$ & 0.73 \\
\hline \multicolumn{7}{|c|}{ Perception of management } \\
\hline Hospital & 75.4 & 18.4 & 80.0 & $78(39.2)$ & $121(60.8)$ & 0.86 \\
\hline Unity & 77.1 & 17.8 & 80.0 & $71(35.7)$ & $128(64.3)$ & 0.76 \\
\hline Working conditions & 71.7 & 27.6 & 75.0 & $70(35.2)$ & $129(64.8)$ & 0.72 \\
\hline
\end{tabular}

Source: Research data, ljuí/RS, Brazil, 2019.

Note: "Results presented in the form n (percentage); A: standardized Cronbach's alpha (aP): coefficient obtained from the covariance of (i.e., adjusted for variability coefficient and the specific size of the sample).

Table 2. Measures of central tendency and variability of workers' $S A Q$ domains. 
Disclose, among all professional categories, the patient safety plan of the institution;

Sensitize all the professionals of the institution about the need for humanization in care, to improve the patient's experience and seek the promotion of safety during care;

Implement the Safe Surgery Protocol as recommended by the NPSP;

Involve the leadership and team professionals in the monitoring and discussion of the results of the safety indicators existing in the institution (falls, hand sanitization, patient identification, medication errors, and pressure injuries);

Provide professionals with a qualified listening environment, with the psychologist available at the institution, to discuss the fragilities about the stress recognition;

Emphasize the effective communication as a goal among the multiprofessional team, starting with the implementation of the reed back method when transmitting/receiving test results;

Intensify the standardization of the electronic prescription routine in all sectors of the hospital.

Figure 1. Priority actions listed by the group.

(c) The coordination of the surgical center, in conjunction with the nursing management, initiated the training of the team to implement the safe Surgery Protocol, as recommended by the National Patient Safety Program. ${ }^{5}$

\subsection{Integrated findings}

In this study, the integration of the results is presented through a joint display in Table $3 .^{27}$ This approach favors a visual representation of understanding and integrating the results of quantitative and qualitative findings, making possible the generation of new metainferences. ${ }^{13}$ During the research study, the decision was made specifically to connect the data related to the negative results of the SAQ to deepen this analysis. Thus, it was expected that the joint display would yield a greater understanding of the factors that would be required for improvements at the study site.

In Table 3, the left side shows the lower quantitative scores of the SAQ in climate areas of safety, working conditions, and stress recognition. The right side presents qualitative data derived from the focus group, which illustrates the participants' perceptions in relation to these areas.

The integrated analysis of data illustrates that the FG participants' responses helped to explain further the results of the statistical analysis of the SAQ. This integrated approach has demonstrated the importance of various aspects of safety culture as a multifaceted phenomenon related to the quality of health care. The following metainferences emerged from the analysis of integrated mixed methods findings:

- The analysis of the SAQ areas receiving the lowest score in the institution reveals the predominance of the perception that the shortcomings in patient safety are an individual's responsibility, generating punitive actions for professionals who might make an error or bring up a patient safety issue. This behavior limits organizational learning because it encourages professionals to cover up errors and not to report incidents, preventing the identification and correction of incidents to prevent future events.

- The shortage of human resources, previously measured by the nursing management through staff size, shows challenges in the institution's working conditions. Workload is high, with the potential negatively to affect quality of care and patient safety.

- The actions of the institution's Patient Safety Team were still incomplete and fragmented, given that the implementation of safety strategies in the institution was directed exclusively to nursing, preventing the participation of multidisciplinary teams in actions to promote patient safety.

- Ineffective communication and failure to pass along important information among multidisciplinary team members created barriers to safe care. 


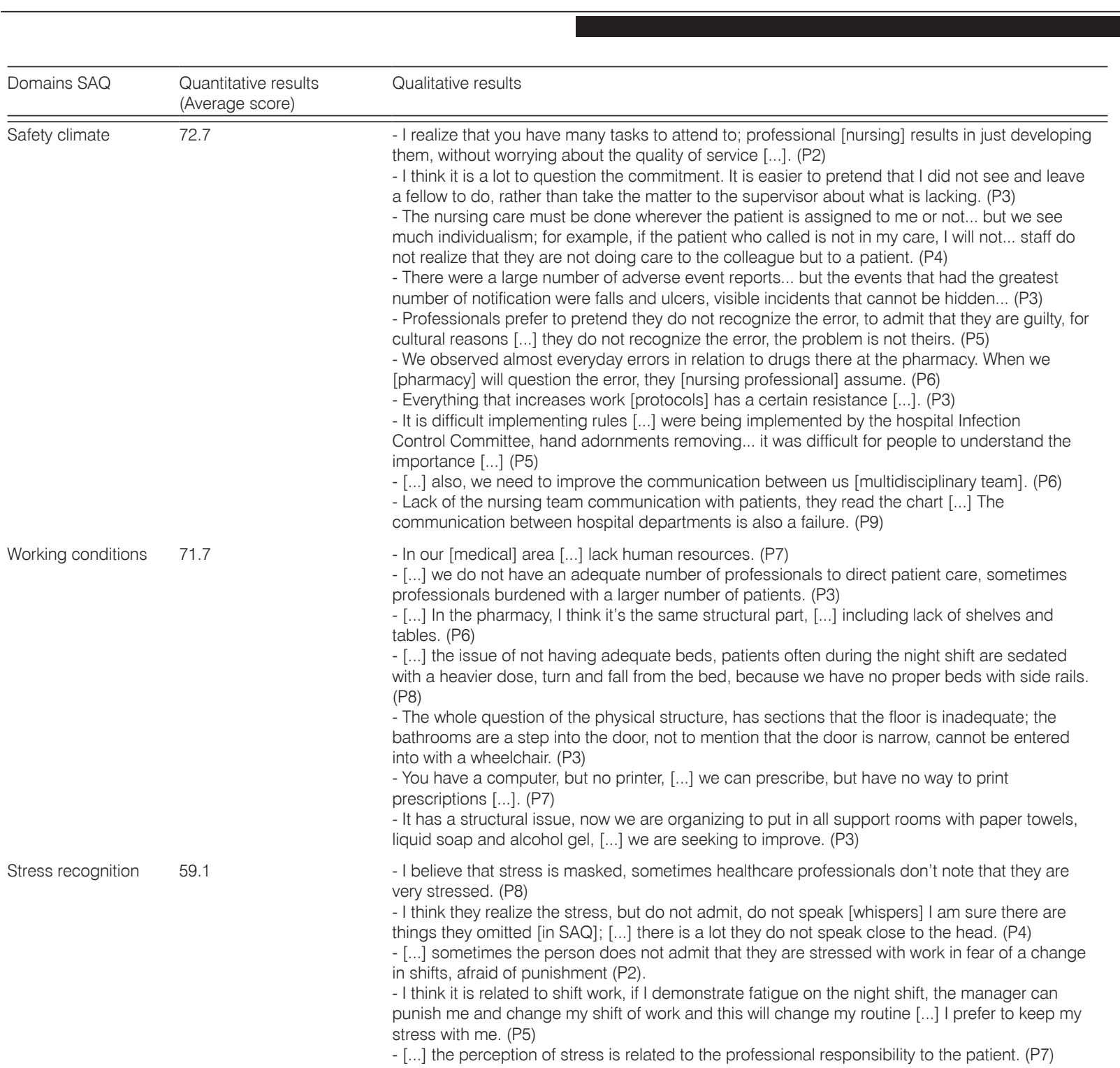

Source: Research data, Alves DFB, ljuí, Brazil, 2019.

Note: SAQ, Safety Attitudes Questionnaire.

Table 3. Quotations of the focus group participants related to the areas of the SAQ that had negative scores.

- The low self-perception of stress among professionals is possibly related to the punitive actions in the institution. Strategies should be strengthened to improve the self-perception of stress among professional categories.

- The use of the DD principles in the FG, as an IKT strategy, enabled the identification of a set of actions to generate improvements in the institution's safety culture, based on the tacit knowledge of the stakeholders and integration and interpretation of scientific evidence.

\section{Discussion}

The response rate to the SAQ was $89.6 \%$. The literature suggests that adequate response rates for climate research should remain between $65 \%$ and $85 \%$ of the population. ${ }^{8}$ The internal consistency of the SAQ scores was assessed through Cronbach's alpha, and the overall result was considered more than adequate $(0.85)$, similar to other studies conducted in Brazil, suggesting that the measuring instrument yields valid scores for the proposed construct. 7,28 
The results showed the predominance of women and the dominance of the category of nursing professionals among the study participants. In Brazil, the nursing team represents the largest contingent of professionals in hospitals, as well as the profession with the highest percentage of women. These data corroborate findings from other national studies that have been reported in recent years. ${ }^{7,29}$

The total scores of the SAQ ranged from 59.1 to 88.7 per domain, with the overall average (75.1) reflecting a positive safety climate in the institution, ${ }^{8}$ differing from most of the other studies wherein the same questionnaire was used in Brazil.7,11,19,28 The positive safety climate we found is probably related to the profile of the institution. It is a medium-sized hospital, and this can be considered a contributing factor to a positive safety climate, according to the findings of a study that assessed 18 types of services in Australia. ${ }^{30}$ Gallego et al. revealed that smaller hospitals, ${ }^{30}$ which provide fewer specialized services, tend to yield a more positive safety culture.

However, by analyzing the specific domains, individual negative scores were found in the areas of "safety climate," "stress recognition," and "working conditions." Evidence suggests that these specific areas need strategies to promote safety in this institution.

The safety climate domain yielded a negative score in our study (72.7), which also was noted in three hospitals in Portugal ${ }^{31}$ and two hospitals in northeastern Italy. ${ }^{32}$ Other Brazilian studies also have produced negative results for this domain..$^{19,33,34}$ These negative safety climate scores suggest a lack of a successful systemic approach to promoting harm-free care. ${ }^{4}$ Indeed, this result points to the need for changes in management errors and incidents systems, understanding them from a systematic approach for professionals to feel free to expose weaknesses in their work processes without fear of punitive measures or retaliation. ${ }^{6}$ Efforts should be directed to improving organizational commitment and adherence to professional guidelines and rules because they are also among the effective measures to improve the safety climate in multidisciplinary teams. ${ }^{35}$ To encourage staff to report errors by creating a nonpunitive environment where errors are examined and potentially solved is widely acknowledged to be an important step toward safety culture environments and in improving patient safety.

The low score found in the working conditions domain indicates that the study participants recognized the need for improvement in this area with a view to a more secure and positive practice environment. Similar results were found in studies conducted in Brazil. ${ }^{11,36,37}$ The weakness identified in this area points to the need for interventions that promote the training of professionals, availability of necessary information for diagnostic and therapeutic discussions, and efficient equipment and proper maintenance and quality infrastructure. In addition, the lack of staffing, work overload, lack of resources, and lack of materials and supplies compromise the quality of care and contribute to professionally reduced job satisfaction and burnout. ${ }^{35}$ For health systems to improve excellence in care, working conditions need to be a priority.

The stress recognition domain yielded the lowest score in the study, 59.1, as noted by other researchers using the same instrument. ${ }^{34,38}$ These results show that professionals do not recognize that tension and stress can harm their performance. One example is the study by Taylor et al. ${ }^{39}$ wherein the stress was associated with an increase of 1.5-3 times the likelihood of accidents, such as falls, medication errors, and pressure injuries.

Factors related to human resources, such as fatigue of professionals due to excessive workload, barriers in communication, ineffective interpersonal relationships, distractions, and the emotional factor of the professionals, are closely linked to the recognition of stress and might negatively affect the development of safe care. ${ }^{6}$ Thus, it is important that health professionals recognize stress as a factor detrimental to their health and impacting patient safety.

Results from the qualitative approach support and sustain the results of the quantitative approach. During the discussions in the FGs, participants were able to discuss factors that exercised a negative influence on patient safety culture. Some punitive actions were mentioned as a factor contributing to the underreporting of adverse events. A study of 7 Brazilian hospitals revealed that the open discussion of adverse events was considered to be a positive factor in the search for improvements, as a consequence of cultivation of the understanding among staff that the detection of these events can serve as a basis for decision-making and planning for improvements in patient safety through the analysis, monitoring, minimizing, and preventing of incidents that cause adverse events. ${ }^{40}$

Ineffective communication in the multidisciplinary team, manifested by the difficulty of professionals to express themselves in front of their peers or leaders, also was a factor that corroborated the negative score in the safety climate domain. A study investigating the concerns that arise between doctors and nurses during the work revealed that they often failed to share problems related to job performance, their knowledge gaps, their relationship problems, and the occurrence of adverse events. As in our study, while acknowledging that such an attitude jeopardizes patient safety, health care workers preferred to remain silent for fear of leaving their current position or being transferred from the sector. ${ }^{41}$ 
Research indicates that inadequate communication has been one of the main factors contributing to the occurrence of adverse events and, consequently, decrease in the quality of care..$^{42}$ To improve communication processes, we recommend the use of tools available in the literature, such as structured communication protocols, briefing (before) and debriefings (after) the implementation of certain procedures, standardization of information about the patient (SBAR), and read back, which constitute effective ways to overcome the barriers to ineffective communication.

The use of DD is an innovative perspective in health research and allows the connection between the empirical evidence and the tacit knowledge of the participants to initiate and implement intentional changes in practice, and to explore a new way of building scientific knowledge. ${ }^{12}$ An example of this was the beginning of actions proposed in the FG meeting, which began even before the end of the research. Among them, the meeting of the patient safety team with leaders was conducted to publicize the NPSP of the institution, and in this meeting, all participants pledged to make the necessary disclosures to all professionals on their respective teams. Also noteworthy was the meeting of the nursing management during all shifts of nursing coordinators to present the results of existing safety indicators in the institution to identify potential threats and to help prioritize actions to prevent harm.

\section{Conclusions}

The findings revealed a positive safety culture in this healthcare organization, as identified by the multidisciplinary team.

Participants in the FG meeting contributed substantially to produce an explanation concerning aspects that resonated negatively in the score domains, safety climate, stress recognition, and working conditions. Among these aspects, ineffective communication stood out, as did a lack of commitment and adherence to protocols and the non-recognition of stress and errors. The participants also mentioned weaknesses in infrastructure, such as the lack of human, financial, and material resources.

The strategy of using a mixed methods research approach made it possible to explain aspects of safety culture that could not be understood using only one approach, and describes the processes of change or reformulation identified by professionals to improve the culture of patient safety in the institution. The use of the DD principles in the study as an IKT strategy enabled us to identify and plan joint actions to generate improvements in safety culture, based on tacit knowledge and the local context of the stakeholders and the integration and interpretation of scientific evidence.

For these reasons, we believe that the analysis of safety culture in an integrated manner using a mixed methods research approach, coupled with the application of the principles of DD, can be the basis for management and policy makers in developing and implementing effective strategies to improve patient safety. Furthermore, this study also shows the need for further research in the area, making it possible to explore the phenomenon in different contexts. In addition, more research is needed to determine whether changes are sustainable and to change the culture of safety with a reduction in adverse events. From a policy or practice perspective, this study provides important information for managers in that these methods might be useful in the implementation of strategies that aim to consolidate a safety culture in health care institutions.

\section{Ethical approval}

This study was approved by the ethics committee of the Regional University of the Northwest of the State of Rio Grande do Sul (UNIJUÍ) (IRB approval number: 2,355,933).

\section{Conflicts of interest}

All contributing authors declare that no conflicts of interest exist.

\section{References}

1. Reis GA, Hayakawa LY, Murassaki AC, Matsua LM, Gabriel CS, Oliveira ML. Nurse manager perceptions of patient safety strategy implementation. Texto Contexto Enferm. 2017;26:e00340016.

2. Stichler JF. Exploring the interface between healthcare design and high-reliability organization initiatives. HERD. 2017;10:17-21.
3. de Souza AB, Maestri RN, Röhsig V, et al. In-hospital falls in a large hospital in the south of Brazil: a 6-year retrospective study. Appl Nurs Res. 2019;48:81-87.

4. National Patient Safety Foundation. Free from harm: Accelerating patient safety improvement Fifteen Years after To err is human. 2015. https:// 
www.aig.com/content/dam/aig/america-canada/us/ documents/brochure/free-from-harm-final-report. pdf. Accessed February 26, 2020.

5. BRASIL. Ministério da Saúde. Gabinete do Ministro. Portaria $n^{\circ} 529$, de $1^{\circ}$ de abril de 2013. Institui o Programa Nacional de Segurança do Paciente. Brasília. http://bvsms.saude.gov.br/bvs/saudelegis/gm/2013/ prt0529_01_04_2013.html. Accessed February 26, 2020.

6. Morello RT, Lowthian JA, Barker AL, McGinnes R, Dunt D, Brand C. Strategies for improving patient safety culture in hospitals: a systematic review. BMJ Qual Saf. 2013;22:11-18.

7. de Carvalho REFL, Arruda LP, do Nascimento NKP, Sampaio RL, Cavalcante MLSN, Costa ACP. Assessment of the culture of safety in public hospitals in Brazil. Rev Lat Am Enfermagem. 2017;25:e2849.

8. Sexton JB, Helmreich RL, Neilands TB, et al. The safety attitudes questionnaire: Psychometric properties, benchmarking data, and emerging research. BMC Health Serv Res. 2006;6:44.

9. Gabrani A, Hoxha A, Simaku A, Gabrani JC. Application of the Safety Attitudes Questionnaire (SAQ) in Albanian hospitals: a cross-sectional study. BMJ. 2015;5:e006528.

10. Huang $\mathrm{CH}, \mathrm{Wu} \mathrm{HH}$, Chou $\mathrm{CY}$, Dai $\mathrm{H}$, Lee $\mathrm{YC}$. The perceptions of physicians and nurses regarding the establishment of patient safety in a regional teaching hospital in Taiwan. Iran J Public Health. 2018;7:852-860.

11. Lorenzini E. Patient safety culture: Mixed Methods Study. Porto Alegre: Programa de Pós-Graduação em Enfermagem, Universidade Federal do Rio Grande do Sul; 2017. http://lume.ufrgs. br/handle/10183/158408. Accessed February 26, 2020.

12. Acosta AM, Oelke ND, Lima MA. Theoretical considerations of deliberative dialogue: contributions for nursing practice, policy, and research. Texto Contexto Enferm. 2017;26:e0520017.

13. Creswell JW. A concise introduction to mixed methods research. Thousand Oaks: Sage; 2015.

14. Fetters MD, Freshwater D. Publishing a methodological mixed methods research article. J Mixed Methods Res. 2015;9:203-213.

15. Molina-Azorin JF, Fetters MD. The journal of mixed methods research starts a new decade. J Mixed Methods Res. 2017;11:143-155.

16. Onwuegbuzie AJ, Hitchcock JH. Towards a cross-cultural mixed research meta-framework for assessing teaching effectiveness in Higher Education. Int $J$ Mult Res Approaches. 2018;10:199-218.
17. Lorenzini E. Mixed-method research in the health sciences. Rev Cuid. 2017;8:1549-1560.

18. Onwuegbuzie AJ, Collins KM. A typology of mixed methods sampling designs in social science research. Qual Rep. 2007;12:281-316.

19. de Carvalho REFL, Cassiani SHDB. Cross-cultural adaptation of the Safety Attitudes Questionnaire Short Form 2006 for Brazil. Rev Lat Am Enfermagem. 2012;20:575-582.

20. Kinalski DDF, de Paula CC, Padoin SMM, Neves ET, Kleinubing RE, Cortes LF. Focus group on qualitative research: experience report. Rev Bras Enferm. 2017;70:424-429.

21. Lorenzini E, Oelke ND, Marck PB, Dall'Agnol CM. Researching safety culture: deliberative dialogue through a restorative lens. Int J Qual Health Care. 2017;29:745-749.

22. Freire P. Pedagogy of the oppressed. New York: Continuum; 1997.

23. Boyko JA, Lavis JN, Dobbins M. Deliberative dialogues as a strategy for system-level knowledge translation and exchange. Healthc Policy. 2014;9:122-131.

24. Lorenzini E, Banner D, Plamondon K, Oelke N. A call for knowledge translation in nursing research. Texto Contexto Enferm. 2019;28:e20190104.

25. Banner D, Bains M, Carroll S, et al. Patient and public engagement in integrated knowledge translation research: are we there yet? Res Involv Engagem. 2019;5:8.

26. Plamondon KM, Bottorff JL, Cole DC. Analyzing data generated through deliberative dialogue: Bringing knowledge translation into qualitative analysis. Qual Health Res. 2015;25:1529-1539.

27. Guetterman TC, Fetters MD, Creswell JW. Integrating quantitative and qualitative results in health science mixed methods research through joint displays. Ann Fam Med. 2015;13:554-561.

28. Kolankiewicz AC, Loro MM, Schmidt CR, Santos FP, Bandeira VA, Magnago TS. Patient safety climate among nursing staff: contributing factors. Acta Paul Enferm. 2017;30:531-537.

29. Kolankiewicz ACB, Schmidt CR, de Carvalho REFL, Spies J, Dal Pai S, Lorenzini E. Patient safety culture from the perspective of all the workers of a general hospital. Rev Gaúcha Enferm. 2020;41:e20190177.

30. Gallego B, Westbrook MT, Dunn AG, Braithwaite J. Investigating patient safety culture across a health system: multilevel modelling of differences associated with service types and staff demographics. Int J Qual Health Care. 2012;24:311-320.

31. Aguas R, Araujo C, Soares S. Safety Attitudes Questionnaire - Intensive Care Unit Version: 
adaptation and validation for the Portuguese population. Rev Enf Ref. 2017;15:101-108.

32. Nguyen G, Gambashidze N, Ilyas SA, Pascu D. Validation of the safety attitudes questionnaire (short form 2006) in Italian in hospitals in the northeast of Italy. BMC Health Serv Res. 2015;15:284.

33. Santiago THR, Turrini RNT. Organizational culture and climate for patient safety in Intensive Care Units. Rev Esc Enferm USP. 2015;49:123-130.

34. Alves DFB, Lorenzini E, Kolankiewicz ACB. Patient safety climate in a Brazilian General Hospital. Int J Risk Saf Med. 2020;31:97-106.

35. Gawron MFG, Oselame GB, Neves EB. Safety culture assessment in health institutions by nursing professionals. Rev Bras Pesq Saúde. 2016;18:6167. https://www.researchgate.net/profile/ Eduardo_Neves/publication/335285830_Avaliacao_da_cultura_de_seguranca_das_instituicoes_ de_saude_por_profissionais_de_Enfermagem/ links/5d6ac7d8a6fdcc547d701f28/Avaliacao-dacultura-de-seguranca-das-instituicoes-de-saudepor-profissionais-de-Enfermagem.pdf. Accessed February 26, 2020.

36. Barbosa MH, Floriano KF, Nascimento KG, Ferreira LA. Patient safety climate at a private hospital. Texto Contexto Enferm. 2016;25:e1460015.
37. Carvalho PA, Gottems LBD, Pires MRGM, de Oliveira MLC. Safety culture in the operating room of a public hospital in the perception of healthcare professionals. Rev Lat Am Enfermagem. 2015;23:1041-1048.

38. Alzahrani N, Jones R, Abdel-Latif ME. Attitudes of doctors and nurses toward patient safety within emergency departments of two Saudi Arabian hospitals. BMC Health Serv Res. 2018;18:736.

39. Taylor JA, Dominici F, Agnew J, Gerwin D, Morlock $\mathrm{L}$, Miller MR. Do nurse and patient injuries share common antecedents? An analysis of associations with safety climate and working conditions. BMJ Qual Saf. 2012;21:101-111.

40. Françolin L, Gabriel CS, Bernardes A, Silva AEBC, Brito MFP, Machado JP. Patient safety management from the perspective of nurses. Rev Esc Enferm USP. 2015;49:277-283.

41. Maxfield DG, Lyndon A, Kennedy HP, Keeffe DO, Zlatnik MG. Confronting safety gaps across labor and delivery teams. Am J Obstet Gynecol. 2013;209:402-408.e3.

42. El-Jardali F, Jaafar M, Dimassi H, Jamal D, Hamdan $R$. The current state of patient safety culture in Lebanese hospitals: a study at baseline. Int J Qual Health Care. 2010;22:386-395. 